\title{
STUDY OF ODONTOGENIC TUMORS IN THE FACULTY OF DENTISTRY ALEXANDRIA UNIVERSITY AND THE POSSIBLE ROLE OF NESTIN AS A MARKER Saleh $\mathrm{M} \mathrm{M}^{1} B D S$, Darwish Z E ${ }^{2} P h D$, Riad S E $P h D$, Medra A $\mathrm{M}^{3} P h D$
}

\begin{abstract}
:
Introduction: Odontogenic tumors constitute a wide range and diverse kind of lesions derived from the tooth forming apparatus and its remnants. They originate from epithelium, ectomesenchyme or both. Varying degrees of inductive interaction between these embryonic components of the developing tooth germ exist. Nestin is one of the intermediate filaments constituting the cytoskeleton and is known as a marker of neural stem cells or progenitor cells. Human Nestin expression continues during tooth development and disappears when development is complete.

Aim of the work: To study the expression of Nestin in different odontogenic tumors, and to highlight the incidence of odontogenic tumors in the Faculty of dentistry, Alexandria University, Egypt in the past 10 years.

Material and Methods: Immunohistochemical analysis was performed on 22 surgical specimens of odontogenic tumors and one control specimen from normal tooth germ.Immunohistochemical staining was performed using a Labeled Strept-Avidin Biotin complex method (LSAB).

Results:Almost all the ameloblastomas were negative for Nestin while all cases of odontogenic fibromyxoma, myxoma and odontogenic fibroma showed intense brownish cytoplasmic reaction in both the ectomesenchymal cells and the odontogenic epithelial rests. Ameloblastic fibroma and ameloblastic fibro-odontom cases showed immunopositivity of Nestin in the ameloblast like cells and stellate reticulum like cells as well as the stromal cells. Calcific structures such as dentinoid as well as hamartomatous lesions mainly odontomes were completely negative for Nestin. The results of the statistical analysis revealed higher prevalence of keratocystic odontogenic tumor followed by ameloblastoma.

Conclusion:Nestin is expressed in some odontogenic tumors in which the ectomesenchyme of the neural crest origin, constituting a part of their proliferated tissue. In the statistical analysis which was done in this study,there was statistical difference regarding types.
\end{abstract}

Keywords: odontogenic tumors, Nestin, ectomesenchymal tumors, intermediate filaments.

1.Instructor at Oral Pathology Department, Faculty of Dentistry, Alexandria University.

2.Professor Oral Pathology Department, Faculty of Dentistry, Alexandria University.

3. Professor Cranio Maxillofacial and Plastic Surgery, Faculty of Dentistry, Alexandria University.

\section{INTRODUCTION}

Odontogenic tumors constitute a wide range and diverse kind of lesions derived from tooth forming apparatus and its remnants (1). They originate from epithelium, ectomesenchyme or both, showing varying degrees of inductive interaction between these embryonic components of the developing tooth germ (2). Therefore, Odontogenic tumors are exclusively found within the jaw bones or in the soft tissue overlying the tooth bearing areas. These tumors may be detected at any time of an individual's life (3).

The relative frequency of odontogenic tumors (OTs) obtained from studies in different parts of the world, have varied widely. Some authors have reported that they are rare with a relative frequency of $1 \%(4)$, while others have reported that they constitute up to $32 \%$ of jaw lesions (5).

Nestin is one of the intermediate filaments constituting the cytoskeleton and is known as a marker of neural stem cells or progenitor cells (6-8). This protein appears at an early developmental stage of both the central nervous system and muscles. Although the function of nestin in cell differentiation is not clearly understood, Nestin is replaced by glial fibrillary acidic protein (GFAP) and desmin, accompanied by developmental processing of nervous and muscular tissues $(6,9)$. Nestin expression has been reported in other tissues and pathological conditions such as neural crest (6), heart (10), testis (11), reactive astrocytes after brain injury (12-14), and central and peripheral nervous system tumors $(15,16)$. It may also be regulated by hypoxia.

The bone marrow niche which contains nestin-positive progenitor cells is hypoxic (17).

Regarding the tooth development and dental pathological conditions, odontoblasts producing dentine in the human and rodent tooth germ express Nestin $(18,19)$. Dentinal fibers and pulp cells adjacent to the odontoblasts at the tooth cusp region also indicate localization of Nestin. Human Nestin expression continues during tooth development and disappears when development is complete (18).In the mature tooth with caries or after cavity formation, Nestin is re-upregulated in odontoblasts and their processes when they are stimulated by caries or when they form the secondary dentine after injury $(18,20,21)$. Thus, Nestin is considered to be related to the differentiation toward odontoblasts and to the acquisition of their function to produce dentine.

The aim of the present work was to study the expression of Nestin in different odontogenic tumors, and to highlight the incidence of OTs cases submitted to the Faculty of dentistry, Alexandria University in the past 10 years.

\section{MATERIALS AND METHODS}

The present study included 22 cases of different odontogenic tumors: 5 cases of ameloblastoma , 4 cases of odontogenic myxoma, 4 cases of ameloblastic fibroma, 4 cases of odontome, 2 cases of calcifying epithelial odontogenic tumors (pindborg tumor), only a case of adenomatoidodontogenic tumor, odontogenic fibroma, and ameloblastic carcinoma, one case for each. The cases were collected from the Cranio-Maxillofacial and Plastic Surgery Department at the Faculty of Dentistry, Alexandria University.

One surgical specimen was taken from tooth germ serving as negative control .The specimens were fixed in $10 \%$ neutral buffered formalin, processed and embedded in paraffin wax using the conventional procedures. Serial sections of 3-4 $\mu \mathrm{m}$ thick were placed on glass slides and stained using hematoxylin and eosin (H\&E), and Immunohistochemical (IHC) staining was performed using the Labeled Strept-avidin biotin complex method (LSAB). 
Then, the sections were examined by the image analyzer computer system using the software Leica Qwin 500 . The device includes a light microscope cabled to a microcomputer that performs high speed digital image processing *.

\section{Statistical Analysis}

Analysis of data was performed using SPSS 17 (Statistical Package for Scientific Studies) for windows year.

The difference in the mean area percent and mean optical density of Nestin immuno-expression for more than two groups like in different odontogenic tumors were estimated using analysis of variance (ANOVA) test.

A (P) value less than 0.05 was considered highly significant. The values are given as a mean value $\pm \mathrm{SD}$ (standard deviation).

\section{RESULTS}

In the present study, a total of 22 patients with odontogenic tumors were included. Nine cases $(40.9 \%)$ were diagnosed as epithelial odontogenic tumors, eight cases $(36.36 \%)$ as mixed odontogenic tumors and five cases $(22.72 \%)$ as mesenchymal odontogenic tumors. The patients' age ranged between 3 and 74 with a mean of 38 years. Ten cases $(45 \%)$ were males and twelve cases $(54 \%)$ were females with a ratio of $1: 1$.

Pattern of Nestin immunostaining in the tooth germ (control group):

The tooth germ included in this study showed immunoreactivity for Nestin in the epithelial cells of the enamel organ and the remnant of dental lamina. Negative reaction in the dentine like tissue was also noted.

\section{Pattern of Nestin immunostaining in tumors of odontogenic epithelium without odontogenic ectomesenchyme}

Out of the 5 examined ameloblastoma cases, 3 were of conventional type and 2 of unicystic type. All the 3 conventional ameloblastoma cases showed immunopositivity for Nestin with different intensities. The follicular ameloblastoma showed immunoreaction of Nestin in both odontogenic epithelial and connective tissue cells (Fig 1A). In the desmoplastic variant of ameloblastoma, Nestin expression was detected as evident brownish reaction in the central stellate reticulum like cells. While in the plexiform ameloblastoma, intense immunoreaction for Nestin was noticed in most of the odontogenic epithelial cells.

The 2 cases of unicystic ameloblastoma which included in the present study were mural and luminal type. The mural type revealed immunonegativity of Nestin in the odontogenic epithelial cells with evident cytoplasmic reaction in some stellate reticulum like cells (Fig 1B), while the luminal type showed evident cytoplasmic reaction of Nestin in the odontogenic epithelial cells (the ameloblast like cells and the vacuolated stellate reticulum like cells).

Two cases of calcifying odontogenic tumor (Pindborg tumor) were included in this study. It showed cytoplasmic immunopositivity for Nestin with different intensities in the polyhedral odontogenic epithelial cells. The amyloid like material is free from any reaction. (Fig 2)

The only examined case of adenomatoid odontogenic tumor revealed positive immunoreaction of Nestin in the epithelial cells and the connective tissue cells.

Only one case of ameloblastic carcinoma was included in the current research. It exhibited cytoplasmic immunopositivity of Nestin in the malignant odontogenic epithelial cells as well as in the keratinized cells (Fig 3A). An interesting finding was the presence of Nestin reaction in the malignant ameloblast like cells with evident basilar hyperplasia. (Fig 3B)
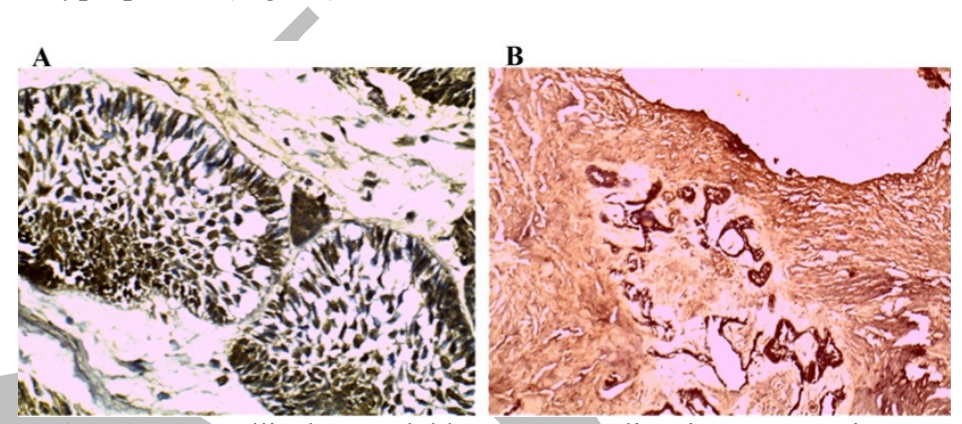

Fig. (1): A- Follicular ameloblastoma revealing immunoreaction of Nestin in both odontogenic epithelial cells and connective tissue cells (x100).

B- Mural ameloblastoma showed immunonegativity of Nestin in the odontogenic epithelial cells with evident cytoplasmic reaction in some stellate reticulum like cells (x100)

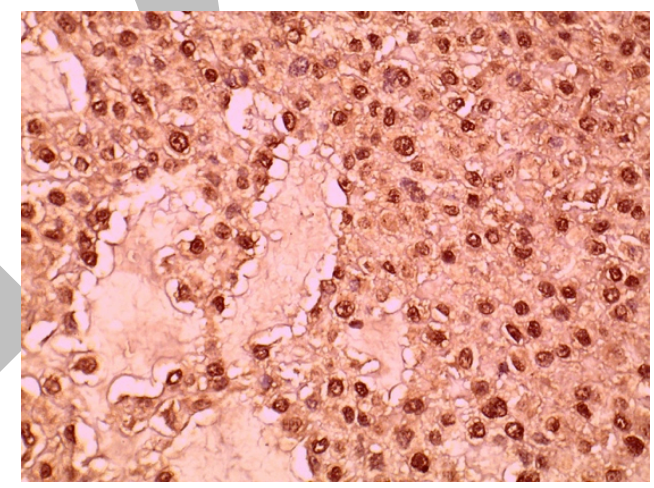

Fig. (2): Pindborg tumor showing cytoplasmic immunopositivity of Nestin with different intensities in the polyhedral odontogenic epithelial cells, the amyloid like material is free from any reaction $(\mathrm{x} 100)$.
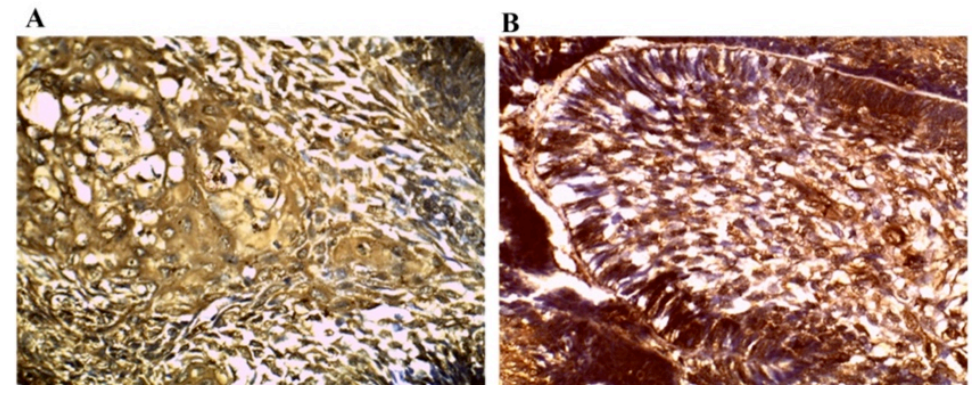

Fig. (3): A- Ameloblastic carcinoma showed cytoplasmic immunopositivity for Nestin in the malignant odontogenic epithelial cells as well as the keratinized cells (x100). B- Ameloblastic carcinoma showed immunopositivity for Nestin in the malignant ameloblast like cells with evident basilar hyperplasia (x100). 


\section{Pattern of Nestin immunostaining in tumors of odontogenic mesenchyme and/or odontogenic ectomesenchyme}

All cases of odontogenic myxoma (Fig 4A) and odontogenic fibroma (Fig 4B) showed evident immunopositivity of Nestin in both the odontogenic stellate ectomesenchymal cells and the odontogenic epithelial rests.

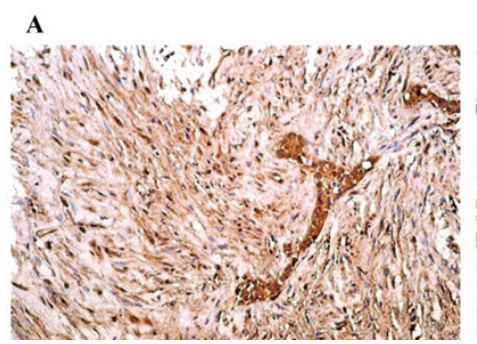

B

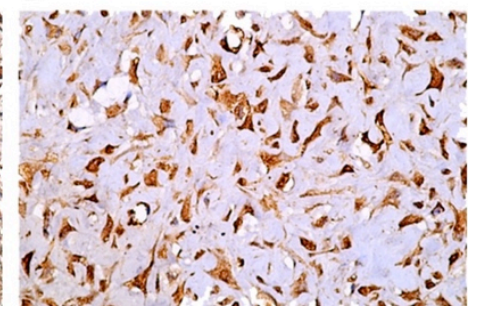

Fig. (4): A- Fibromyxoma showed evident immunopositivity for Nestin in the odontogenic stellate cells as well as the odontogenic epithelial rests (x200).

B- Odontogenic fibroma showed intense cytoplasmic immunoreaction of Nestin in the fibroblast cells (x400).

\section{Pattern of Nestin immunostaining in the tumors of odontogenic epithelium with odontogenic ectomesenchyme}

Ameloblastic fibroma (Fig 5A) and ameloblastic fibroodontome (Fig 5B) cases showed immunopositivity of Nestin in the ameloblast like cells and stellate reticulum like cells and in the connective tissue cells. However, the dentine like tissue showed negative Nestin expression.

Compound and complex odontomes showed cytoplasmic immunopositivity of Nestin in the pulpal cells and negative reaction in the dentin like tissue was noted. (Fig. 6A, 6B)

Both mean area percent and mean optical density of Nestin in all odontogenic tumor cases were correlated using the image analyzer computer system.

The difference in mean Nestin area percent and mean optical density between epithelial, ectomesenchymal, and mixed odontogenic tumors using $F$ test (ANOVA) revealed high significant difference, $(\mathrm{p}<0.001)$. (Table 1,2$)$

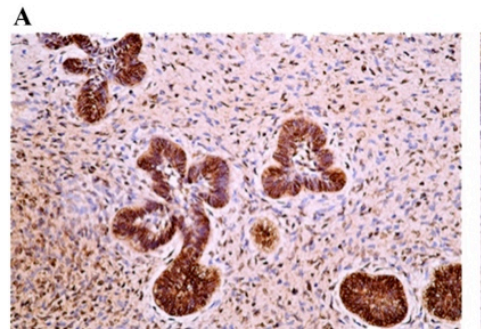

B

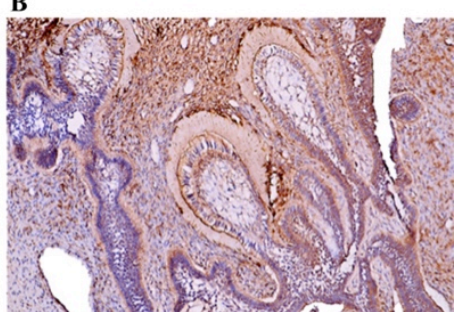

Fig. (5): A- Ameloblastic fibroma showed immunopositivity for Nestinin the ameloblast like cells, stellate reticulum like cells as well as the connective tissue cells (x200).

B- Ameloblastic fibro-odontome showing evident immunoreaction of Nestin in the odontogenic epithelial cells and negative reaction in the dentine like tissue (x100).
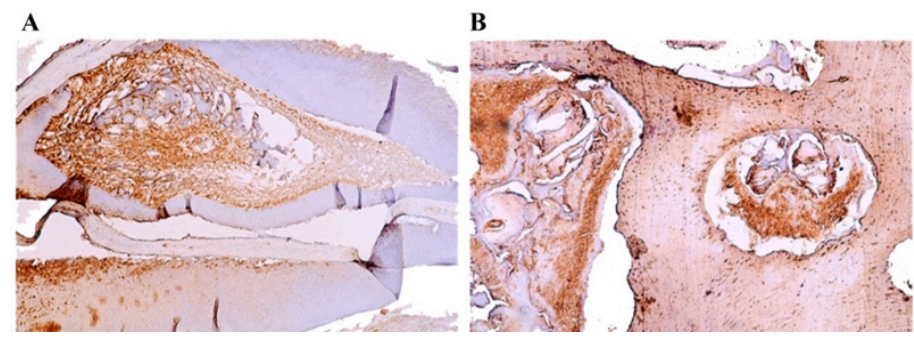

Fig. (6): A- Compound odontome revealing cytoplasmic immunopositivity of Nestin in the pulpal cells and negative reaction in the dentin like tissue (x200).

B- Complexodontome showing evident immunopositivity of Nestin in the pulpal cells and negative reaction in the dentine like tissue (x200)

Table (1): Comparison between the three studied groups according to area percent.

\begin{tabular}{|c|c|c|c|c|c||}
\hline & $\begin{array}{c}\text { Epithelial } \\
(\mathbf{n}=\mathbf{9})\end{array}$ & $\begin{array}{c}\text { Mesenchymal } \\
(\mathbf{n}=\mathbf{5})\end{array}$ & $\begin{array}{c}\text { Mixed } \\
(\mathbf{n}=\mathbf{8})\end{array}$ & $\mathbf{F}$ & $\mathbf{p}$ \\
\hline Area\% & & & & & \\
Min. - Max & $5.40-23.17$ & $19.84-31.43$ & $33.64-54.92$ & & \\
Max. \pm SD & $12.57 \pm 6.03$ & $26.68 \pm 4.87$ & $40.76 \pm 7.21$ & $42.676^{*}$ & $<0.001^{*}$ \\
Median & 12.93 & 27.11 & 38.78 & & \\
\hline Sig. bet. Grps & \multicolumn{2}{|c|}{$\mathrm{p}_{1-0}-001^{\circ}, \mathrm{p}_{2}<0.001^{*}, \mathrm{p}_{3}-0.001^{*}$} & & \\
\hline
\end{tabular}

F: F test (ANOVA), Sig. bet. Grps was done using Post Hoc test (LSD)

$\mathrm{p}_{1}$ : $\mathrm{p}$ value for comparing between Epithelial and Mesenchymal $\mathrm{p}_{2}$ : $\mathrm{p}$ value for comparing between Epithelial and Mixed

$\mathrm{p}_{3}$ : $\mathrm{p}$ value for comparing between Mesenchymal and Mixed

*: Statistically significant at $\mathrm{p}<0.05$

Table (2): Comparison between the three studied groups according to mean optical Density.

\begin{tabular}{||c|c|c|c|c|c||}
\hline & $\begin{array}{c}\text { Epithelial } \\
(\mathbf{n}=\mathbf{9})\end{array}$ & $\begin{array}{c}\text { Mesenchymal } \\
(\mathbf{n}=\mathbf{5})\end{array}$ & $\begin{array}{c}\text { Mixed } \\
(\mathbf{n}=\mathbf{8})\end{array}$ & $\mathbf{F}$ & $\mathbf{p}$ \\
\hline $\begin{array}{c}\text { Mean Opt D } \\
\text { Min. - Max }\end{array}$ & $49.50-62.20$ & $52.52-63.21$ & $68.11-83.30$ & & \\
Max. \pm SD & $54.85 \pm 4.29$ & $57.35 \pm 5.11$ & $75.81 \pm 5.51$ & $42.336^{*}$ & $<0.001^{*}$ \\
Median & 54.60 & 55.50 & 76.85 & & \\
\hline \multicolumn{7}{|c|}{$\mathrm{p}_{1}-0.376, \mathrm{p}_{2}<0.001^{*}, \mathrm{p}_{3}<0.001^{*}$} & & \\
\hline
\end{tabular}

F: F test (ANOVA), Sig. between groups was done using Post Hoc test (LSD)

$\mathrm{p}_{1}$ : $\mathrm{p}$ value for comparing between Epithelial and Mesenchymal $\mathrm{p}_{2}: \mathrm{p}$ value for comparing between Epithelial and Mixed $\mathrm{p}_{3}$ : $\mathrm{p}$ value for comparing between Mesenchymal and Mixed *: Statistically significant at $p<0.05$

Statistical analysis of odontogenic tumors diagnosed in Oral Pathology Department, Faculty of Dentistry, Alexandria University, in the period from 2003 to 2013 which was done in the present work revealed that two hundred and thirty four cases of odontogenic tumors were diagnosed in this period. Keratocystic odontogenic tumor and ameloblastoma are the most prevalent odontogenic tumors diagnosed in this period. (Table 3) 
Table (3): Most prevalent cases diagnosed in Oral Pathology Depatment during the period from 2003 to 2013.

\begin{tabular}{||c|c|c|c|c|c|c|}
\hline \hline Type & $\mathbf{N}$ & $\%$ & $\begin{array}{c}\text { Age } \\
\text { range }\end{array}$ & $\begin{array}{c}\text { Male } \\
(\%)\end{array}$ & $\begin{array}{c}\text { Female } \\
(\%)\end{array}$ & M:F \\
\hline $\begin{array}{c}\text { Keratocystic } \\
\text { odontogenic tumor }\end{array}$ & 66 & 28.2 & $16-55$ & 31.81 & 68.18 & $1: 2$ \\
\hline Ameloblastoma & 64 & 27.35 & $9-63$ & 62.5 & 37.5 & $1.6: 1$ \\
\hline $\begin{array}{c}\text { Cemanto-0ssifying } \\
\text { fibroma }\end{array}$ & 28 & 11.96 & $13-55$ & 32.14 & 67.85 & $1: 2$ \\
\hline fibromyxoma & 19 & 8.11 & $17-50$ & 42.1 & 57.89 & $1: 1.3$ \\
\hline
\end{tabular}

\section{DISCUSSION}

Nestin is a class VI intermediate filament protein expressed in normal and diseased cells in different tissues and organs (22). Among neural cells in the developing and adult CNS, its expression is thought to occur exclusively in neural progenitor cells (NPCs). After NPCs differentiate, Nestin expression typically is replaced by the expression of neuronal or glial specific markers (23).

In view of expression of Nestin in stem cells of normal human and neoplastic human tissues, several researchers found that Nestin was mainly expressed in ectomesenchymal tumors as they derived from neural crest. They concluded that its expression is not throughout life, but rather during limited periods such as odontogenesis and repair of dentine $(19,20,24)$.

In the current work, Nestin expression exhibited positive immunoreaction in the only examined case of tooth germ. The immune reaction was detected in the epithelial cells of the enamel organ and remnant of dental lamina. However, negative reaction in the dentine like tissue was noted. Similar results were reported by About et al (19).They found that Nestin was first expressed in the bell stage and in pulpal cells located at the cusp area of the fetal teeth and is absent in the dental follicle. In contrast, Morsczeck et al (25) found that Nestin was identified in slices of human dental follicles. Therefore, this intermediate filament is predominantly expressed in a number of stem cells and appears to be a useful molecular marker to characterize precursor cells of neuroectodermal and mesenchymal lineages, for example undifferentiated neural progenitor cells $(6,19,21,26)$.

In the current research, Nestin expression was positive in almost $80 \%$ of the epithelial odontogenic tumors. Some studies were matched with our results; they found that Nestin expression was reported in other epithelial tumors such as breast (27), prostate (28)and pancreatic cancer(29). Moreover,Yang, et al., (30) reported higher percentage of different epithelial tumors showed positive immunoreactivity for Nestin. In contrast, Ohike et al. (29) reported minimal positivity for Nestin in the epithelial tumors. The differences between the studies could be due to differences between the anti-Nestin antibodies that were used by the investigators; they could also be due to differences in histological techniques.

In this immunohistochemical study, the examined ameloblastoma cases showed immunopositivity for Nestin with different intensities. It exhibited immunoreaction in both odontogenic epithelial and connective tissue cells. Moreover, in the desmoplastic variant of ameloblastoma, Nestin expression was detected as evident brownish reaction in the central stellate reticulum like cells only as the ameloblast like cells were unclear due to the collagenous fibrous stroma. In addition, the unicystic ameloblastoma cases showed brownish reaction in the odontogenic epithelial cells lining the cyst wall as well as the fibrous capsule. Conversely, Fujita et al (18) found that ameloblastoma and ameloblastic carcinoma did not express Nestin, except for one benign case that showed focal Nestin localisation in the apical part of the peripheral columnar epithelium of the follicular pattern. On the contrary, our work showed that the only examined case of ameloblastic carcinoma included showed immunopositivity of Nestin in the malignant odontogenic epithelial cells as well as in the keratinized cells.

The present research revealed that the examined cases of calcifying odontogenic tumor (Pindborg tumor) showed immunopositivity for Nestin with different intensities in the polyhedral odontogenic epithelial cells while the amyloid material was free from any reaction.Other studies $(31,32)$ reported that Pindborg tumor could express Nestin marker. This might be due to the fact that tumor cells of Pindborg tumor bear a close morphological resemblance to the cells of the stratum intermedium of the enamel organ, which is which is weakly immuno-reactive in the early bell stage of normal tooth germs.

In the current study, adenomatoid odontogenic tumor revealed cytoplasmic reaction of Nestin in epithelial cells and connective tissue cells. This goes with the results of Fujita et al (18) who found that Nestin was distributed predominantly in the epithelial component.

Concerning the ectomesenchymal odontogenic tumors, almost all cases showed immunopositivity for Nestin. This is accepted by Hoffman (33) and Teranishi et al (34) who found that Nestin was expressed in cells of mesenchymal phenotype,hair follicle stem cells and newly proliferating endothelial cells.

Odontogenic myxomas and odontogenic fibroma revealed immunopositivity in odontogenic stellate ectomesenchymal cells. This is similar to Fujita results (18) which showed almost half the cases of jaw myxoma demonstrated Nestin immunoexpression, this study demonstrated two 
origins of spindle or stellate tumour cells intermingled within the mucoid matrix have been proposed--these are, dental papilla cells of tooth germ, and mesenchymal cells such as fibroblasts or myofibroblasts other than odontogenic ectomesenchyme.

In the present work, $100 \%$ of the mixed odontogenic tumors showed positive immunoreactivity for Nestin.

Ameloblastic fibroma and ameloblastic fibro-odontome cases showed immunopositivity of Nestin in the ameloblast like cells and stellate reticulum like cells and in the connective tissue cells. However, the dentine like tissue showed negative Nestin expression. This is matched with the results of Fujita et al (18) which found some follicular epithelial components showed Nestin localization in both peripheral ameloblastic columnar cells and inner stellate cells, but intense expression in the odontogenic ectomesenchymal element, particularly around the neoplastic follicular odontogenic epithelium which was not a finding in our work.

Compound and complex odontomes showed cytoplasmic immunopositivity of Nestin in the pulpal cells and negative reaction in the dentin like tissue. This results matched with those of Fujita et al (18), which showed Nestin expression in mature odontoblasts and their processes in the dentinal tubules.

Statistical analysis of odontogenic tumors diagnosed in Oral Pathology Department, Faculty of Dentistry, Alexandria University, in the period from 2003 to 2013, in the present work revealed that higher prevalence of keratocystic odontogenic tumors followed by ameloblastomas. It has been accepted by Ebenezer and Ramalinqam (35). In contrast, Jing et al (36), Tawfik and Zyada (37) and Osterne et al (38) reported ameloblastoma to be the most frequent odontogenic tumor in Chinese, Egyptian and Brazilian populations, followed by KCOT and odontoma. In accordance with Tawfik and Zyada (37), these discrepancies probably result from geographic variation and underestimated cases of odontoma.

\section{CONCLUSIONS}

Nestin protein is expressed in some odontogenic tumors especially those arising from ectomesenchymal tissue which is derived from neural crest, so it might be an important diagnostic aid in the differential diagnosis between epithelial, mixed, and ectomesenchymal odontogenic tumors. Nestin associated with human odontogenic ectomesenchyme is not expressed throughout life, but rather during limited periods such as odontogenesis and repair of dentine. In the statistical analysis which was done in this study, there was a statistical difference regarding types. frequency and distribution of odontogenic tumors, compared with studies in other populations which may be attributed to geographic difference.

\section{CONFLICT OF INTEREST}

The authors declare that they have no conflicts of interest.

\section{REFERENCES}

1. Lu Y, Xuan M, Takata T, Wang C, He Z, Zhou Z, et al. Odontogenic tumors. A demographic study of 759 cases in a Chinese population. Oral Surg Oral Med Oral Pathol Oral Radiol Endod. 1998;86(6):707-14.

2. Mosqueda-Taylor A, Ledesma-Montes C, CaballeroSandoval S, Portilla-Robertson J, Ruiz-Godoy Rivera LM, Meneses-Garcia A. Odontogenic tumors in Mexico: a collaborative retrospective study of 349 cases. Oral Surg Oral Med Oral Pathol Oral Radiol Endod. 1997;84(6):672-5.

3. El-Gehani R, Orafi M, Elarbi M, Subhashraj K. Benign tumours of orofacial region at Benghazi, Libya: a study of 405 cases. J Craniomaxillofac Surg. 2009;37(7):370-5.

. Ochsenius G, Ortega A, Godoy L, Penafiel C, Escobar E. Odontogenic tumors in Chile: a study of 362 cases. J Oral Pathol Med. 2002;31(7):415-20.

5. Adebayo ET, Ajike SO, Adekeye EO. A review of 318 odontogenic tumors in Kaduna, Nigeria. J Oral Maxillofac Surg. 2005;63(6):811-9.

6. Lendahl U, Zimmerman LB, McKay RD. CNS stem cells express a new class of intermediate filament protein. Cell. 1990;60(4):585-95.

7. Hendrickson ML, Rao AJ, Demerdash ON, Kalil RE. Expression of nestin by neural cells in the adult rat and human brain. PLoS One. 2011;6(4):e18535.

8. Guerette D, Khan PA, Savard PE, Vincent M. Molecular evolution of type VI intermediate filament proteins. BMC Evol Biol. 2007;7:164.

9. Kachinsky AM, Dominov JA, Miller JB. Myogenesis and the intermediate filament protein, nestin. Dev Biol. 1994;165(1):216-28.

10. Kachinsky AM, Dominov JA, Miller JB. Intermediate filaments in cardiac myogenesis: nestin in the developing mouse heart. J Histochem Cytochem. 1995;43(8):843-7.

11. Frojdman K, Pelliniemi LJ, Lendahl U, Virtanen I, Eriksson JE. The intermediate filament protein nestin occurs transiently in differentiating testis of rat and mouse. Differentiation. 1997;61(4):243-9.

12. Abdel-Rahman A, Rao MS, Shetty AK. Nestin expression in hippocampal astrocytes after injury depends on the age of the hippocampus. Glia. 2004;47(4):299-313.

13. Frisen J, Johansson CB, Torok C, Risling M, Lendahl U. Rapid, widespread, and longlasting induction of nestin contributes to the generation of glial scar tissue 
after CNS injury. J Cell Biol. 1995;131(2):453-64.

14. Holmin S, Almqvist P, Lendahl U, Mathiesen T. Adult nestin-expressing subependymal cells differentiate to astrocytes in response to brain injury. Eur J Neurosci. 1997;9(1):65-75.

15. Dahlstrand J, Collins VP, Lendahl U. Expression of the class VI intermediate filament nestin in human central nervous system tumors. Cancer Res. 1992;52(19):5334-41.

16. Florenes VA, Holm R, Myklebost O, Lendahl U, Fodstad O. Expression of the neuroectodermal intermediate filament nestin in human melanomas. Cancer Res. 1994;54(2):354-6.

17. Spencer JA, Ferraro F, Roussakis E, Klein A, Wu J, Runnels JM, et al. Direct measurement of local oxygen concentration in the bone marrow of live animals. Nature. 2014;508(7495):269-73.

18. Fujita S, Hideshima K, Ikeda T. Nestin expression in odontoblasts and odontogenic ectomesenchymal tissue of odontogenic tumours. J Clin Pathol. 2006;59(3):240-5.

19. About I, Laurent-Maquin D, Lendahl U, Mitsiadis TA. Nestin expression in embryonic and adult human teeth under normal and pathological conditions. Am J Pathol. 2000;157(1):287-95.

20. About I, Mitsiadis TA. Molecular aspects of tooth pathogenesis and repair: in vivo and in vitro models. Adv Dent Res. 2001;15:59-62.

21. Terling C, Rass A, Mitsiadis TA, Fried K, Lendahl U, Wroblewski J. Expression of the intermediate filament nestin during rodent tooth development. Int J Dev Biol. 1995;39(6):947-56.

22. Wiese C, Rolletschek A, Kania G, Blyszczuk P, Tarasov KV, Tarasova Y, et al. Nestin expression--a property of multi-lineage progenitor cells? Cell Mol Life Sci. 2004;61(19-20):2510-22.

23. Dahlstrand J, Lardelli M, Lendahl U. Nestin mRNA expression correlates with the central nervous system progenitor cell state in many, but not all, regions of developing central nervous system. Brain Res Dev Brain Res. 1995;84(1):109-29.

24. McLachlan JL, Smith AJ, Sloan AJ, Cooper PR. Gene expression analysis in cells of the dentine-pulp complex in healthy and carious teeth. Arch Oral Biol. 2003;48(4):273-83.

25. C. Morsczecka T, W. Gftzb JS, F. Zeilhoferc, U. $\mathrm{Ku}$ “hnb CM, C. Sippela e. Isolation of precursor cells (PCs) from human dental follicle of wisdom teeth. Matrix Biology. 2005;24:155-65.

26. Lobo MVT, Arenas MI, Alonso FJM, Gomez G, Bazan E, Paino e. Nestin, a neuroectodermal stem cell marker molecule, is expressed in Leydig cells of the human testis and in some specific cell types from human testicular tumours. Cell Tissue Res.
2004;316(3):369- 76 .

27. Li H, Cherukuri P, Li N, Cowling V, Spinella M, Cole $\mathrm{M}$ e. Nestin is expressed in the basal/myoepithelial layer of the mammary gland and is a selective marker of basal epithelial breast tumors. Cancer Res. 2007;67:501-10.

28. Kleeberger W, Bova GS, Nielsen ME, Herawi M, Chuang AY, Epstein JI, et al. Roles for the stem cell associated intermediate filament Nestin in prostate cancer migration and metastasis. Cancer Res. 2007;67(19):9199-206.

29. Ohike N, Sato M, Hisayuki T, Imataka H, Sato S, Wada $\mathrm{Y}$, et al. Immunohistochemical analysis of nestin and ckit and their significance in pancreatic tumors. Pathol Int. 2007;57(9):589-93.

30. Yang X, Wu Q, Yu X, Xu C, Ma B, Zhang X e. Nestin expression in different tumors and its relevance to malignant grade. J Clin Pathol. 2007.volume no.pages ??

31. Philipsen HP, Reichart PA. Classification of odontogenic tumors. A historical review. J Oral Pathology and Medicine. 2006;35:525-9.

32. Takeda Y, T T. Revised histopathological classification of odontogenic tumors by WHO and its allied epithelial cyst. Japanese $\mathrm{J}$ of Oral and Maxillofacial Surgery. 2006;52:54-61.

33. Hoffman RM. The potential of nestin-expressing hair follicle stem cells in regenerative medicine. Expert Opin Biol Ther. 2007;7(3):289-91.

34. Teranishi N, Naito Z, Ishiwata T, Tanaka N, Furukawa $\mathrm{K}$, Seya T, et al. Identification of neovasculature using nestin in colorectal cancer. Int J Oncol. 2007;30(3):593603.

35. Ebenezer V, Ramalingam B. A cross-sectional survey of prevalence of odontogenic tumours. J Maxillofac Oral Surg. 2010;9(4):369-74.

36. Jing W, Xuan M, Lin Y, Wu L, Liu L, Zheng X, et al. Odontogenic tumours: a retrospective study of 1642 cases in a Chinese population. Int J Oral Maxillofac Surg. 2007;36(1):20-5.

37. Tawfik MA, Zyada MM. Odontogenic tumors in Dakahlia, Egypt: analysis of 82 cases. Oral Surg Oral Med Oral Pathol Oral Radiol Endod. 2010;109(2):e67-73.

38. Osterne RL, Brito RG, Alves AP, Cavalcante RB, Sousa FB. Odontogenic tumors: a 5-year retrospective study in a Brazilian population and analysis of 3406 cases reported in the literature. Oral Surg Oral Med Oral Pathol Oral Radiol Endod. 2011;111(4):474-81. 